\title{
Clam culture in the Venice lagoon: stock assessment of Manila clam (Venerupis philippinarum) populations at a nursery site and management proposals to increase clam farming sustainability
}

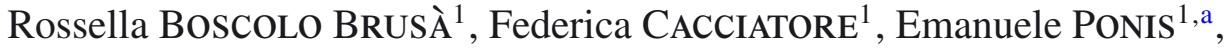 \\ Emiliano MOLIN $^{2}$ and Eugenia DELANEY ${ }^{2}$ \\ 1 ISPRA, Italian National Institute for Environmental Protection and Research, Loc. Brondolo, 30015 Chioggia (VE), Italy \\ 2 Thetis Engineering Division, EU Research and Development Unit, 30122 Venice (VE), Italy
}

Received 4 October 2012; Accepted 21 January 2013

\begin{abstract}
The Venice lagoon is the main Manila clam (Venerupis philippinarum) production site in Europe. Following the unsustainable exploitation of this site (free-access fishery) local authorities have been striving to regulate fishing activities and most clams are produced using mollusc culture techniques based on wild spat harvesting and on its seeding in appropriate, designated culture areas. Therefore, the quality and abundance of wild clam stocks are critical factors that could limit the full development of this activity. The present study aims at assessing Manila clam stocks (spat, adults per square meter) using ordinary kriging, in an area of the Venice lagoon located near the Porto Marghera industrial zone. Previous studies have identified this area as one of the most important natural clam settlement sites in the Venice lagoon. The study area was approximately 1085 ha; 46 sampling stations were examined. Stock assessment (animals were grouped by size and age group), biomass and correlation with sediment texture were evaluated. The results obtained and comparisons with studies from the literature enabled an estimation of clam recruitment potential and an analysis of the conservation status of clam stocks. Thereafter, in view of a full reclamation and an ecological restoration of the study area, different measures are proposed for the sustainable use of this area that include the establishment of a biological protection area and a shared and rational management of the nursery area; these measures could potentially increase the sustainability of clam culture in the Venice lagoon.
\end{abstract}

Keywords: Clam culture / Bivalve / Abundance / Spatial analysis / Spat management / Veneridae / Adriatic Sea

\section{Introduction}

Manila clam Venerupis philippinarum (Adams and Reeve 1850) (synonym: Ruditapes philippinarum) is a native species of the subtropical to low boreal zone of the western Pacific but, due to its high commercial value and its great adaptability and resistance to a wide range of environmental conditions and stressors, it has been introduced into several parts of the world where it has become permanently established. Different factors may explain the successful spread of the Manila clam, such as its high tolerance to variations of environmental parameters (salinity, temperature, dissolved oxygen), its high capability to adapt to different substratum typologies and its high fitness (early gonadic maturation, high fertility, and its long spawning period in which multiple spawning is possible) (Sorokin and Giovanardi 1995; Paesanti and Pellizzato 2000; Pellizzato and Da Ros 2005).

\footnotetext{
${ }^{a}$ Corresponding author: emanuele.ponis@isprambiente.it
}

The first attempts to introduce Manila clam in Italy date from 1983, when a small amount of spat (approx. $3 \mathrm{~kg}$ of $3 \mathrm{~mm}$ size) purchased in an English hatchery was sown in the southern basin of the Venice lagoon (Breber 2002). Some promising results were rapidly achieved and during the 1980s, further sowing attempts were carried out in many Italian transitional sites (in the lagoons of Po delta, Grado and Marano, Lazio, and Sardinia) (Pellizzato and Da Ros 2005; Zentilin et al. 2007; Sladonja et al. 2011). The great suitability of these environments for Manila clam, both in terms of growth and natural reproduction, soon became evident, especially in the case of the Northern Adriatic transitional systems characterized by shallow waters and high freshwater inputs rich in nutrients and high natural productivity. In such areas, the species rapidly spread to all favorable sites and Manila clam harvesting soon became the most economically important fishing activity. Landing data indicate that production peaked at around 64000 tons in 1999 and the Venice lagoon contribution accounted for up to $60 \%$ of Italy's overall production 
(Zentilin et al. 2008). Over the past few decades, there has been a constant decrease in Manila clam production due to the initial lack of reliable regulation and an adopted logic of unsustainable exploitation of fisheries resources (i.e. "collect as much as you can, everywhere"): in 2009 the estimated production for the Venice lagoon was 10000 tons (GRAL 2011). Reasons behind such a decline are (i) indiscriminate exploitation of natural beds, (ii) illegal gathering, (iii) use of high-impacting harvest gears with consequent detrimental effects on sediment and water, (iv) conflicts between fishery and other activities carried out in the Venice lagoon, (v) lack of efficient programming schedules, and (vi) inadequate management of nursery areas (Pranovi et al. 1994; Pellizzato and Da Ros 2005; Melaku Canu et al. 2011).

To deal with this situation, the local government and water authorities have been trying to introduce regulations for the rational management of this activity through the implementation, since 1999, of Master Plans for clam production that aim to control and restore the social, environmental and economic sustainability of this activity.

Among the different directives promoted by the sustainable management plans for clam culture procedures, particular importance was given to the transition from clam fishing to clam farming activities and to the rational management of natural spat. Today in the Venice lagoon, most clam harvesting is carried out in licensed areas that are directly managed by clam farmers. Such areas, divided by the regulatory agency GRAL into concessions, are directly managed by local clam fishermen who have to respect the strict rules applied by GRAL to increase efficiency and sustainability of the farming activity. Fishing is still possible in GRAL-managed areas, with strict access control.

Unlike other forms of mollusc culture, clam farming in Italy is almost exclusively dependent on natural spat collection. Two billion animals $\left(2 \times 10^{9}\right)$ per year is the estimated amount of spat necessary to rationally seed the licensed areas of the Venice lagoon (approx. 3300 ha) (Veneto Agricoltura and Provincia di Venezia 2011). Spat availability is one of the biggest barriers to the full development of clam culture and, accordingly, the rational management of wild spat and the safeguarding of natural nursery areas are considered to be priority tasks for achieving increased sustainability of this practice.

Several studies have investigated the spatial distribution of wild stocks of Manila clam (adults, juveniles, settled postlarvae) in the Venice lagoon (Casale et al. 2001; Penzo et al. 2003; Pessa and Mion 2005; Pellizzato et al. 2011), and the area overlooking the wide Porto Marghera industrial area and Venice (Central Basin) is considered to be one of the major areas naturally rich in both Manila clam adults and juveniles. This area is also known as a "Remediation Site of National Interest" (SNI) in Italy, identified as an area of high environmental risk due to pollutant inputs from the surrounding industrial area over a period of almost 70 years. Porto Marghera is also known as one of the most important chemical districts in Italy (Zonta et al. 2007; Bellucci et al. 2012). This is why clam fishing/farming are forbidden in this area of the lagoon, with the exception of a few spat collection campaigns previously carried out under local authority supervision and through the adoption of strict mitigation procedures. Despite the formal prohibition of harvesting, illegal and indiscriminate exploitation of both spat and commercial-sized clams have been carried out over the years using high-impacting gears (hydraulic and vibrating dredges and rakes), which have led to the impoverishment of resources and have given rise to environmental, social and public health concerns (Melaku Canu et al. 2011).

One of the most important goals of the Remediation Project of the Venice-Porto Marghera SNI includes restoring the entire area to legitimate uses, such as clam farming. In order to manage sustainable activity concerning clams, knowledge of clam distribution and stock assessment is necessary. The present study aims at improving knowledge of a portion of the SNI zone that has been previously identified by several studies as one of the most important nursery areas of the Venice lagoon. The annual mean salinity value recorded in the area was 32\%o (data collected monthly in 2008, Ministry of Infrastructures and Transports - Magistrato alle Acque).

Biometric and gravimetric data were processed in order to evaluate annual recruitment, distribution of size classes and potential relationships between Manila clam abundance, biomass and sediment texture (Shepard's classification). Moreover, the comparison between current and bibliographical data has enabled an estimation of the health condition of Manila clam stocks in the area.

Different measures will be proposed to increase mollusc culture sustainability in the Venice lagoon through rational resource management (establishment of a biological protection zone, shared and sustainable management of the nursery area).

\section{Materials and methods}

\subsection{Sampling procedures}

Sampling surveys were conducted during November 2009. Such a time window was chosen in order to include the most recent cohorts (current year spring and summer spawning) in the analysis.

A nested sampling strategy was used and 46 stations located in the tidal flat were sampled (Fig. 1). Higher sampling density was chosen in the north-eastern study area, or the area indicated by previous studies (Casale et al. 2001; Pessa and Mion 2005) with a higher density of Manila clam adults and juveniles. Stations were sampled using an EkmanBirge grab (surface area $225 \mathrm{~cm}^{2}$ ) or, in case of difficulty due to excess sediment compaction, using a cylindrical sample corer (surface area $78.5 \mathrm{~cm}^{2}$ ). In both cases, a core of at least $25 \mathrm{~cm}$ depth of sediment was collected for each sampling (5 samplings per station using the Ekman-Birge grab, 15 samplings per station using the cylindrical sample corer). Sediments were washed and sieved on board through a $1 \mathrm{~mm}^{2}$ meshed sieve. Samples of Venerupis spp. were then collected and transferred to the laboratory. Clam species were identified ( $V$. philippinarum, $V$. decussata) and individually measured (shell length - considered as the maximal length parallel to the hinge - recorded to the nearest millimeter using a dial caliper) and weighed (fresh weight, rounded to the nearest centigram). Sediment granulometry was assessed in a previous measurement campaign carried out in the same area in 2006 


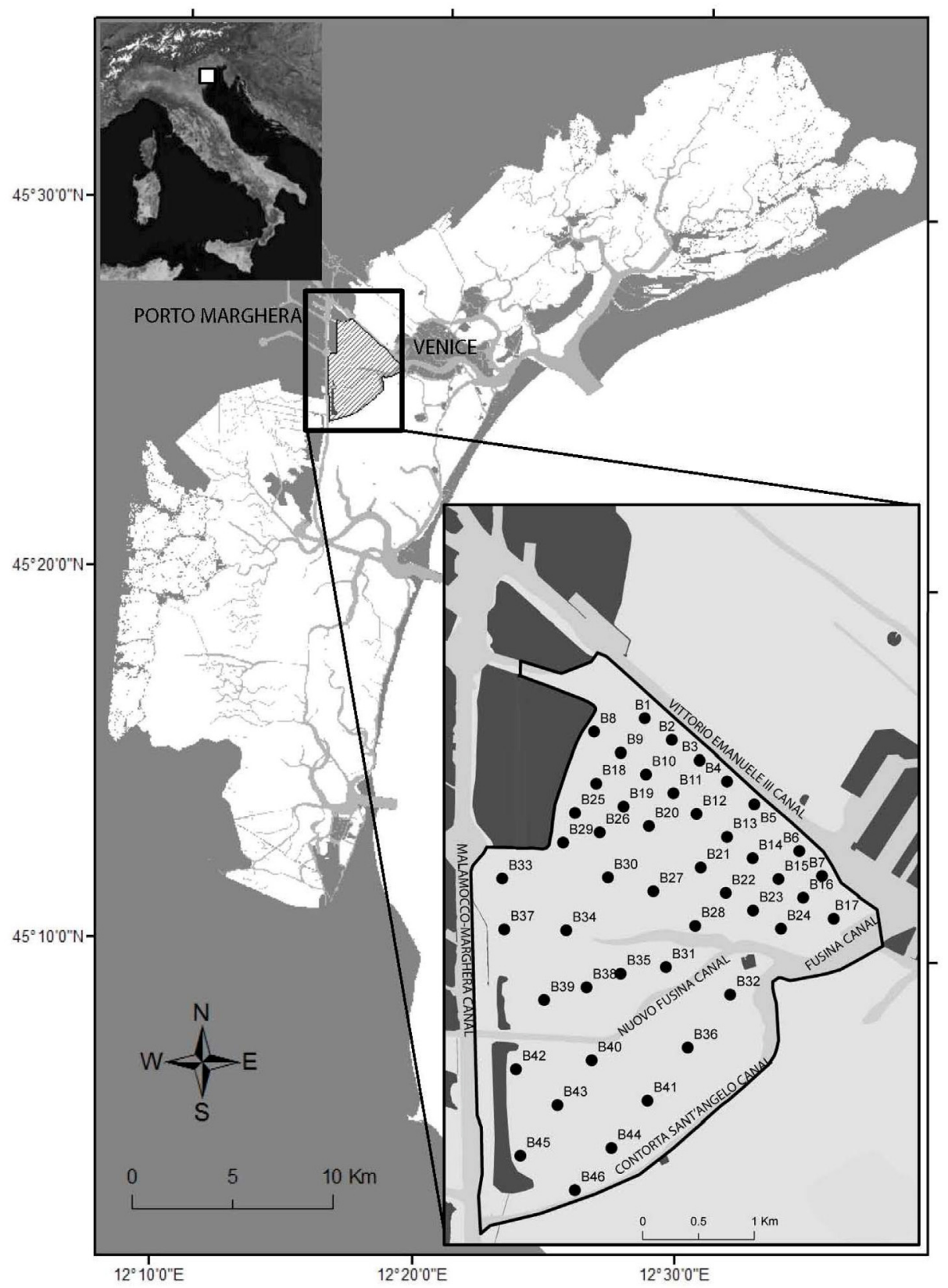

Fig. 1. Location of the study area and locations of the stations sampled for the Manila clam stock assessment.

(Ministry of Infrastructures and Transports - Magistrato alle Acque, through its concessionary Consorzio Venezia Nuova, unpublished data), during which 221 stations were sampled by a sediment vibro-corer (diameter $10 \mathrm{~cm}$ ); the level considered for this analysis was $0-25 \mathrm{~cm}$. For each of the 46 stations sampled in clam survey, the sediment values found in the nearest sediment sampling station were associated.

\subsection{Analysis methods}

Georeferencing of data and spatial analysis (clam total and spat abundance, commercial size biomass) were performed using ArcGIS 10 (ESRI) software. Shepard's values, as modified by Schlee (1973), were calculated using the US Geological Survey (USGS) ArcMap Sediment Classification tool (O’Malley 2007).

Application of the linear geostatistical method, like ordinary kriging, requires the assumption that data follow a second-order stationarity pattern (data comes from a random process with a constant mean; spatial covariance depends only on the distance and direction separating any two locations).

Interpolated data maps for total clam and spat abundance were obtained using ordinary kriging: experimental semivariograms and spatial model fitting for total clam and spat abundance were performed taking into account some experimental 
Table 1. Description of the geostatistical methods (ordinary kriging) adopted and the parameters of the fitted variograms (CV: cross validation).

\begin{tabular}{lccc}
\hline & Fig. 3 & Fig. 4 & Fig. 4 \\
& Presence/Absence & Presence/Absence & Abundance \\
\hline Transformation & None & None & Log $(x+1)$ \\
\hline Trend & None & Second & Second \\
Model & Spherical & Stable & Stable \\
Anisotropy & No & No & No \\
Lag size & 368.8 & 368.8 & 368.8 \\
Nugget & 0.03 & 0.00 & 0.02 \\
Sill & 0.25 & 0.16 & 0.34 \\
Range & 1017 & 639 & 639 \\
CV error mean & -0.009 & -0.011 & -0.016 \\
CV root-mean-square standardized & 0.977 & 1.058 & 0.929 \\
\hline
\end{tabular}

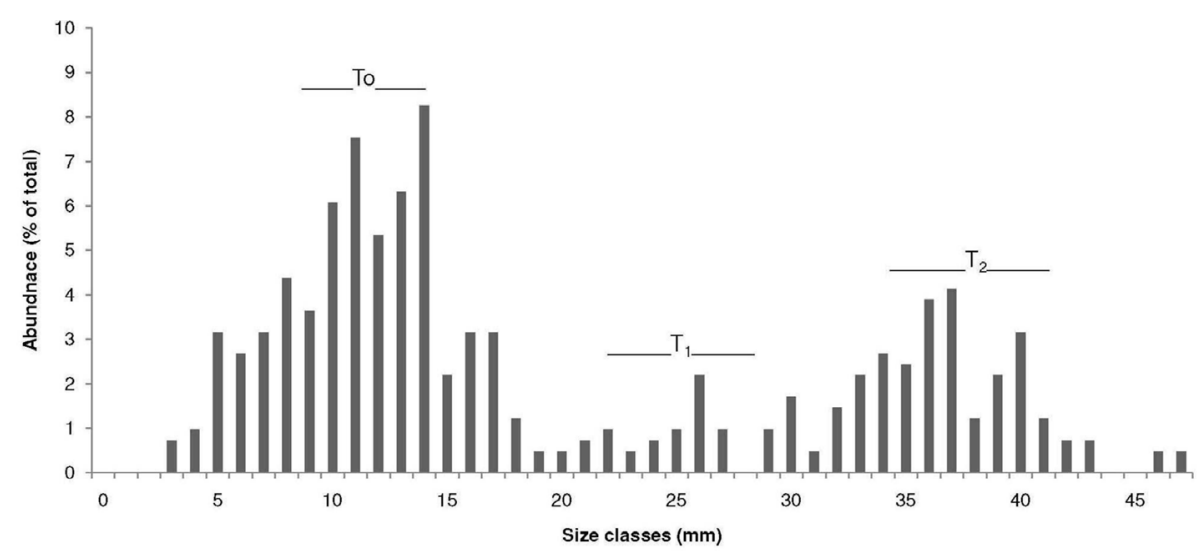

Fig. 2. Frequency distribution of size and age groups of Venerupis philippinarum. T0, T1, T2: different recruitment years.

work from the literature on mollusc stock spatial analysis (Sauriau and Bacher 1991; Warren 1997; Morsan 2003). Lag size was selected using the Average Nearest Neighbor function of ArcMap 10.

The spatial analysis of data highlighted a non-negligible proportion of zero catches and a strong positively skewed distribution of Manila clams. Hence, a spatial analysis was performed adopting a two-stage procedure, according to Warren (1997), for the spatial analysis of scallops: (1) use of an indicator variable $(0,1)$ denoting the absence or presence of Manila clam to estimate the occupied area; (2) ordinary kriging of the mean conditional on there being Manila clams present. The threshold value used in the maps for assuming clam presence is 0.5 both for clam and spat total abundance.

The main parameters used for interpolation by kriging are summarized in Table 1.

An estimation of commercial-sized clams (size $\geqslant 29 \mathrm{~mm}$, according to local regulations) was assessed in the area to evaluate the commercial stocks available for fishery management purposes. In this case, the typology of available data was weakly defined by the empirical variograms and the interpolation technique using kriging was not feasible. In this case, maps were obtained using the inverse distance weighting technique.

The chi-square test was applied to assess equivalent distribution of sediment texture (Shepard's number) among Manila clam class abundance and biomass categories.

\section{Results}

\subsection{Stock assessment}

During the survey, a total of 413 specimens of Venerupis spp. were collected in the area, all of which belonged to the Venerupis philippinarum species (except for one $V$. decussata specimen).

The size class distribution of the collected animals is represented in Figure 2. The multimodal distribution identified clearly refers to different age groups and, over the same year, to different cohorts (multiple spawning over the same reproductive season). In general, most of the sampled animals referred to the current year recruitment (T0). These specimens $(<20 \mathrm{~mm})$ accounted for more than $62 \%$ of the total number of clams found. The second year (T1) cohorts were poorly represented, probably as a consequence of low recruitment success (T2 abundance higher than T1). Commercial-sized clams (>29 mm) represented $30 \%$ of the total sampled specimens. Specimens of $V$. philippinarum were found in 26 sampling sites, or in $57 \%$ of the overall monitored stations. A higher abundance was detected in the north-eastern zone, with particular reference to the area overlooking the Vittorio Emanuele III canal, with values reaching 497 animals per $\mathrm{m}^{2}$ (station B6) and average abundances $>300$ animals per $\mathrm{m}^{2}$.

The overall distribution of Manila clams was concentrated in a few areas located in the central and northern part of the study area, whereas the southern part exhibited a very limited amount of specimens or, sometimes, none at all; it 


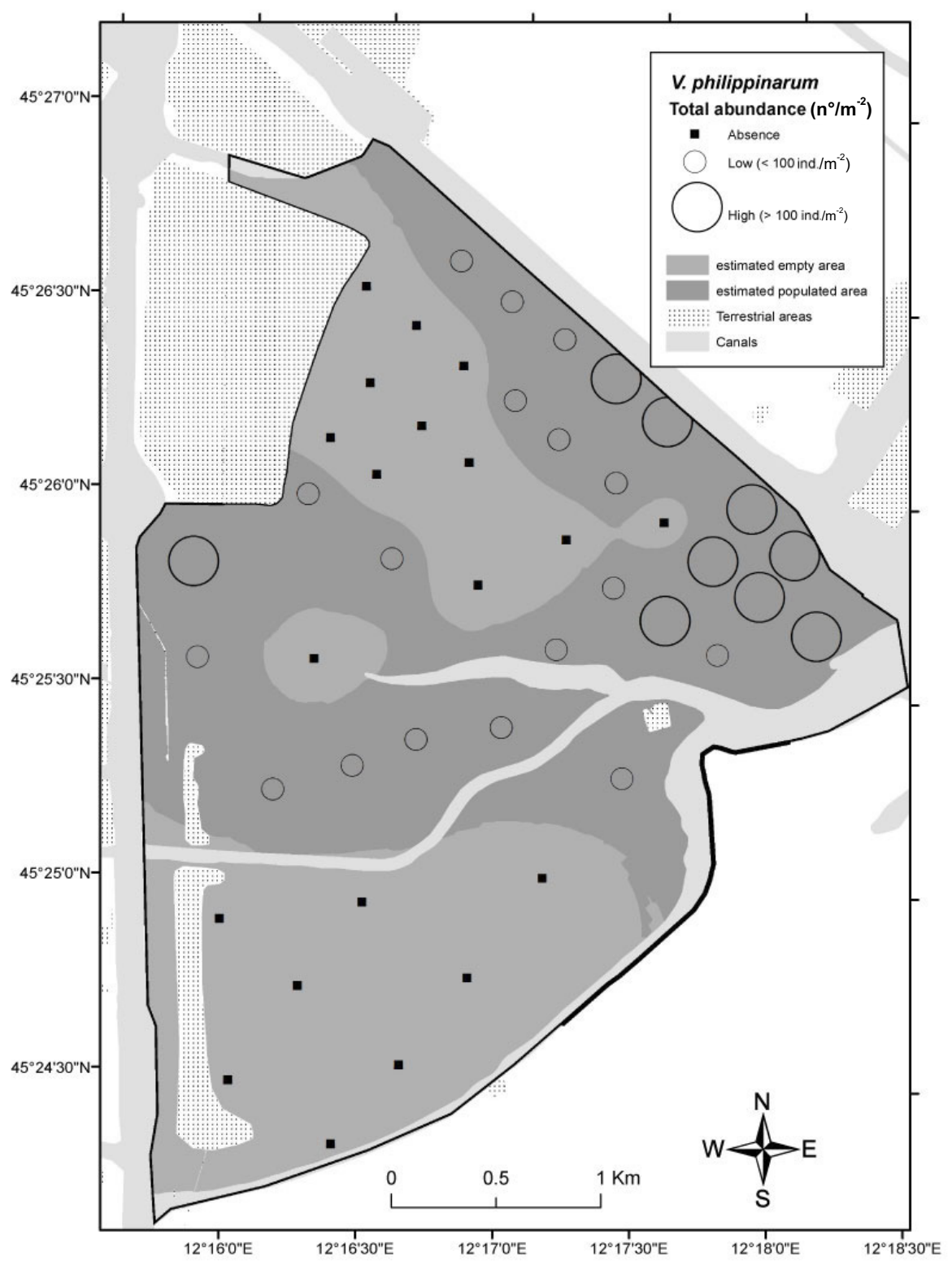

Fig. 3. Abundance map (ind. $\mathrm{m}^{-2}$, ordinary kriging) of Venerupis philippinarum in the study area.

can be assumed that this area had an unsuitable habitat for V. philippinarum.

The empirical variogram, obtained using the variables 0 , 1 as an indicator denoting the respective absence/presence of Manila clam, fitted well with the spherical model and led to a kriged estimate of the mean of 0.5563 . Accordingly, a surface of 481.4 ha (or $44 \%$ of the total study area) is estimated as being unoccupied. The empirical variogram of non-zero data was obtained after a log transformation of data. A spherical model was adopted, albeit with a considerable degree of uncertainty; the calculated kriged mean was 75.05 , which lead to an overall density, in the areas where the species was present, of $0.5563 \times 75.05=41.75$ ind. $\mathrm{m}^{-2}$.

The spatial distribution of $V$. philippinarum abundance is displayed as well as the area previously estimated as suitable for their populations (Fig. 3). Stations were grouped into three classes according to abundance found: absence, low $\left(<100\right.$ ind. $\left.\mathrm{m}^{-2}\right)$ and high $\left(\geqslant 100\right.$ ind. $\left.\mathrm{m}^{-2}\right)$ density.

A similar approach was adopted to estimate the distribution of young recruited spat (size $<20 \mathrm{~mm}$, Fig. 4). In this case, the estimated variogram (second trend removal, model stable) gave a mean value of 0.3582 , corresponding to an occupied total area of approx 389 ha. The map confirms the high abundance found in the north-eastern zone of the study area. The amount of spat that could be harvested for clam culture purposes (density $\geqslant 100$ ind. $\mathrm{m}^{-2}$ ) was assessed by a further interpolation (ordinary kriging) superimposed onto the same map.

Results showed a heterogeneous distribution of commercial clam distribution in the area and a biomass superior to 


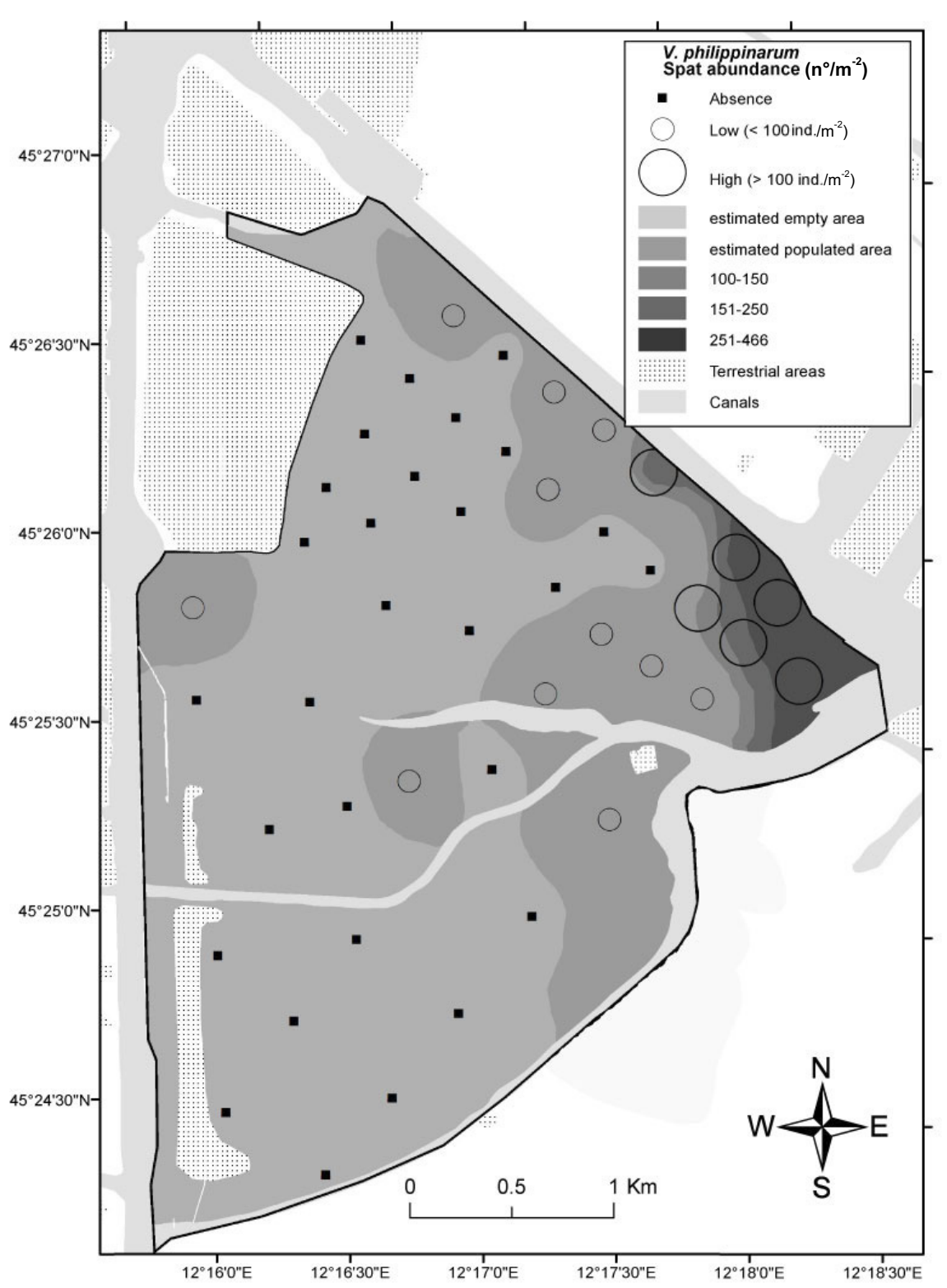

Fig. 4. Venerupis philippinarum spat abundance (ind. $\mathrm{m}^{-2}$; ordinary kriging). The map contains two different interpolations overlapped: (1) presence/absence kriged zones; (2) High density (>100 ind. $\mathrm{m}^{-2}$ ) kriged areas.

$1 \mathrm{~kg} \mathrm{~m}^{-2}$ in the different stations (B2, B16, B23, B29 and B33) of the study area. One consequence of such high heterogeneity of commercial-sized stocks is the unsuitability of the kriging method for obtaining an interpolation map and to have a reliable estimation of the exploitable area for fishery purposes. The map was obtained with the Inverse Distance Weighting technique (Fig. 5). Three main areas with a high density of V. philippinarum were found: A) an area located in the inner area of the study zone; B) and C) areas located in the proximity of Vittorio Emanuele III and Fusina canals. The $\mathrm{C}$ area partially overlaps with the largest nursery area found in the present study, indicating the high suitability of this location for $V$. philippinarum. In this way, an overall high biomass area $\left(>1 \mathrm{~kg} \mathrm{~m}^{-2}\right.$ ) was estimated, representing $6 \%$ of the entire study area, equivalent to 66.2 ha. Table 2 shows a summary of the main estimation results obtained, together with the different spatial analysis techniques applied in the present study.

\subsection{Sediment structure}

The entire study area is mainly characterized by heterogeneous sandy-silt and silty-sand textures, except for a small area that has a coarser granulometry (sand, gravel) located in the north-eastern area of the study zone (data not shown). The distribution of abundance and biomass categories are distributed 


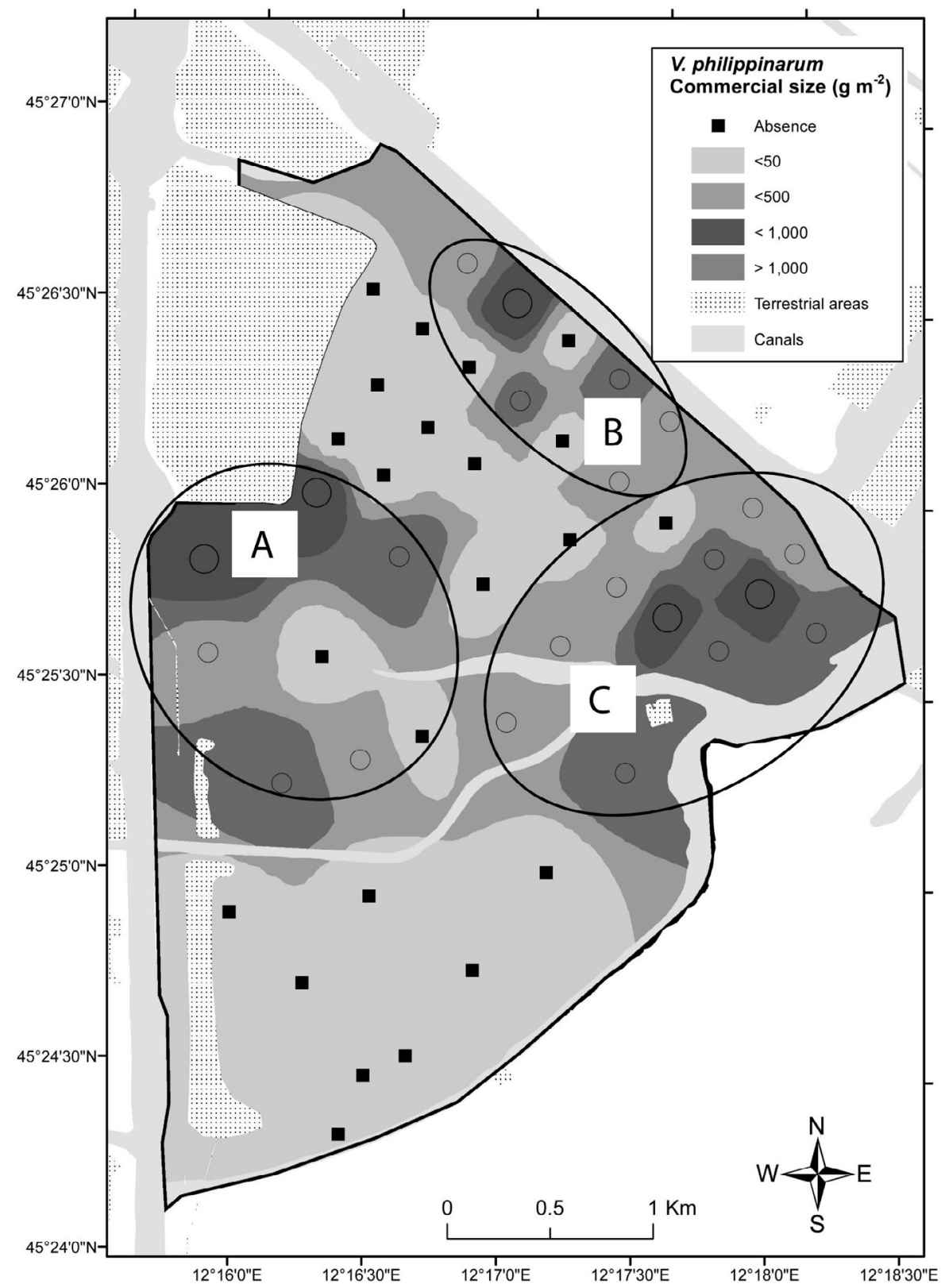

Fig. 5. Inverse Distance Weighting of commercial-sized clam stock. Letters and ellipses indicate the areas with higher densities.

Table 2. Main outcomes obtained when applying the spatial analysis to the study area. Surface areas are calculated in hectares $(100 \times$ $100 \mathrm{~m})$.

\begin{tabular}{lcc}
\hline & \multicolumn{2}{c}{ Surface } \\
& (ha) & $(\%)$ \\
\hline Study area & 1085.0 & 100 \\
Empty area & 481.4 & 44 \\
Occupied area (all cohorts) & 603.3 & 56 \\
Occupied spat area $_{\left.\text {Exploitable spat area (>100 ind. } \mathrm{m}^{-2}\right)}$ & 388.7 & 36 \\
Proposed sanctuary area (approx.) & 290.2 & 6 \\
\hline
\end{tabular}

among sediment texture according to Shepard's classification (Fig. 6). Both for abundance and biomass, the results found that higher values were associated with coarser sediment (gravelly, sandy silt). The chi-square test showed significant association only among abundance classes and sediment texture $\left(\chi^{2}=21.1 ; p<0.05\right)$.

\section{Discussion}

In this research, Manila clam stocks were examined and assessed in a site of the Venice lagoon previously identified by other studies as one of the most important natural nursery areas for clams. Results confirmed an aggregated distribution of $V$. philippinarum, with the presence of high spatial heterogeneity in abundance and biomass, even in adjacent areas, for both juveniles and adults. Such a distribution typology was previously observed by Casale et al. (2001) for the concerned area and, more generally for fisheries survey data, 


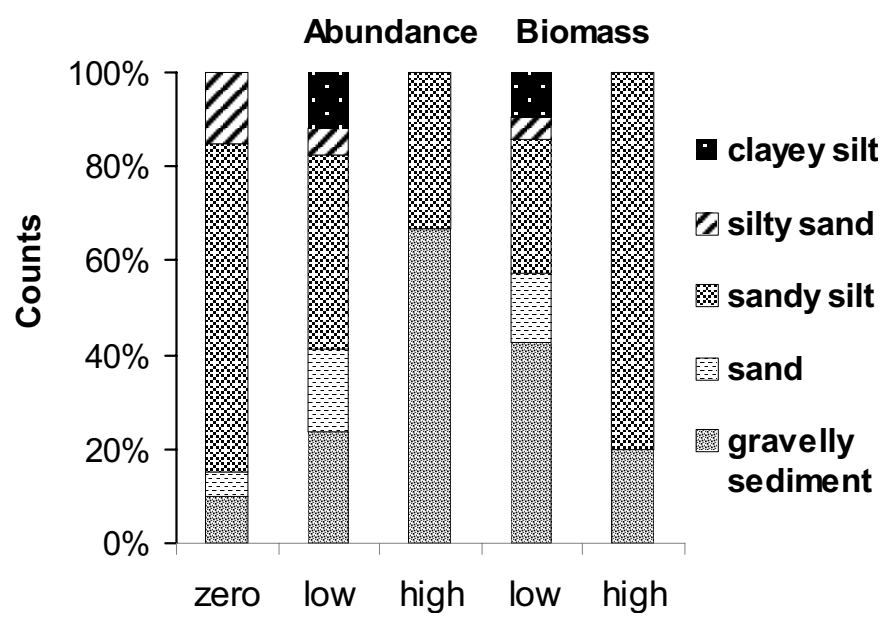

Fig. 6. Frequency of sediment texture (Shepard's classification) found in stations sampled for Manila clam stock assessment. Stations were grouped in abundance (zero: no clam, low $<100$ ind. $\mathrm{m}^{-2}$, high $\geqslant$ 100 ind. $\mathrm{m}^{-2}$ ) and biomass (low $<1000 \mathrm{~g} \mathrm{~m}^{-2}$, high $\geqslant 1000 \mathrm{~g} \mathrm{~m}^{-2}$ ) categories.

by Warren (1997). The distribution only seemed to be patchier in the case of commercial-sized clam biomass. Different parameters concur to determine the spatial distribution of Manila clam settlement areas and adult stocks. In the first case, hydrodynamic and topographical conditions are driving factors (Nambu et al. 2012), whereas recruitment success is affected by multiple factors such as broodstock quality, meteo-climatic conditions during spawning, hydrodynamics, mortality rate of larvae and juveniles, and predation (Ólafsson et al. 1994).

Among the different environmental factors influencing spatial distribution and potential yield of V. philippinarum, the application of a Random Forest algorithm to the Venice lagoon has recently identified salinity, sand percentage in the sediment and depth as the most influential parameters (Vincenzi et al. 2011). Sediment data indicated that sandy-silt and silty-sand textures represented the main components with a coarser patch located in the north-eastern part of the study area, in proximity to the confluence of two big canals (Vittorio Emanuele III and Fusina; data not shown); the high abundances of both juvenile and adult $V$. philippinarum found in this area confirm the strong positive relationship between coarser sediment percentage and Manila clam abundance (Vincenzi et al. 2011), even though other factors such as hydrology and local trophic conditions, not investigated in this study, could also be involved.

The distribution of $V$. philippinarum (juveniles and adults) has been investigated in previous studies (Casale et al. 2001; Penzo et al. 2003; Pessa and Mion 2005; Pellizzato et al. 2011), where high abundance and biomass of clams were found in the part of the lagoon between the city of Venice and the Porto Marghera industrial zone. Hydrological conditions carry a large amount of $V$. philippinarum settling larvae to this area, which find local abiotic and biotic characteristics adequate to sustain them.

The investigation conducted in 1999 by Casale et al. (2001) aiming to verify the abundance and distribution of the most important clam species in the entire Venice lagoon, highlighted that most Manila clams were found in the central basin $(89 \%$ of the total amount). In particular, the area between Venice and the Porto Marghera industrial zone (including the present study area) exhibited the highest densities of juvenile stages (up to 4000 ind. $\mathrm{m}^{-2}$ ); therefore, this zone may be considered as the main "nursery area" of the whole lagoon. Moreover, consistent biomasses of adults (up to $6000 \mathrm{~g} \mathrm{~m}^{-2}$ of specimens $>25 \mathrm{~mm}$ ) were found. A successive study carried out in 2002 confirmed high abundance and biomass in this area, even if lower values were detected in comparison with the 1999 data (Pessa and Mion 2005). During the period 2002-2007, several surveys were carried out in 25 sampling stations distributed within the lagoon in order to identify the most significant nursery areas (Pellizzato et al. 2011). This study confirmed that the Remediation Site of National Interest (SNI) is one of the most important nursery sites of the lagoon, even if large fluctuations were observed. Abundances and biomasses found during the present survey were remarkably lower than those in the bibliographical data collected for the same area, both for adult and juvenile stocks (Casale et al. 2001). Such reduction is consistent with the one observed, at a larger scale, for the Venice lagoon (Melaku Canu et al. 2011). Possible causes for this decline are related to variations in larval settlement, limited recruitment (caused by overfishing, predation, diseases, etc.), local or global environmental changes (Tezuka et al. 2012) and engineering work such as channel dredging and construction of an artificial island in the nearby area. In the specific case of the Venice lagoon, a significant reduction in primary production has been observed over the past few decades as a result of a considerable reduction in nutrient loads (Solidoro et al. 2010 and references therein).

In recent years, local institutions have made efforts to increase the sustainability of clam culture in the Venice lagoon, which still represents one of the area's main occupational and economic fishery activities: 900 people are involved in this industry in the Venice lagoon, while its annual income is estimated at about 85-100 million $€$ (GRAL 2009; Melaku Canu et al. 2011). Among the different measures promoted, particular attention was given to the transition from an open-access system to extensive aquaculture (clam farming) and to a better exploitation and management of clam recruits. Rational management of this resource has not yet been achieved in the Venice lagoon. Good results were, however, obtained with similar objectives in the Sacca di Goro (North Adriatic), one of the most important sites for Manila clam farming in Italy. Nursery areas were identified, georeferenced and declared as protected areas. Their management is shared among all the fishermen's cooperatives under a regional committee (Servizio Economia Ittica, Regione Emilia Romagna), with the support of a scientific institute (Istituto Delta Ecologia Applicata). Local fishermen directly manage these areas to optimize their potential capacity and to preserve the resource for common use (macroalga and bioclast removal, addition of sediment, prevention of illegal harvesting) and the frequent surveys conducted to estimate available stocks allow a correct scheduling of spat harvesting campaigns, which are regulated by strict access controls. During the first seven campaigns, 2.1 billion $\left(2.1 \times 10^{9}\right)$ spat were collected and then distributed to the various fishermen's cooperatives according to available surface area per person (Regione Emilia-Romagna 2010). 
In this vein, proficient management of the study area for clam farming purposes, once its environmental reclamation and restoration has been achieved, could contribute to increase sustainability of clam culture in the Venice lagoon.

Firstly, the north-eastern zone of the area should be managed as a nursery. Considering a proficient collection to be a harvest of at least $100 \mathrm{~V}$. philippinarum spat per $\mathrm{m}^{2}$, a portion of 59 ha was identified with an abundance of approx. 160 million spat (Fig. 4, darkest kriged area). This amount would efficiently cover the seeding of 80 ha of licensed clam farming area (seeding density: 200 ind. $\mathrm{m}^{-2}$; precautionary estimated amount of mortality and/or predation of $25 \%$ ). Considering a wholesale price of $4 € \mathrm{~kg}^{-1}$ for Manila clam adults (Mauracher et al. 2010) and a commercial size of $35 \mathrm{~mm}$, income generated by the seeding of such an amount would be $5.3 \times 10^{6} €$.

Commercial-sized clam distribution is too heterogeneous to envisage efficient exploitation. Nevertheless, a management strategy that could add value to the available stocks is the setting up of lagoon protected areas (sanctuaries) in which clam harvesting is prohibited; this could contribute to restoration and protection of spawning stock biomass and the support of shellfish populations in areas surrounding the sanctuary itself. Spawning sanctuaries are considered to be an effective strategy when native, wild stocks face pressure from excessive fishing and recruitment limitation, as well as habitat destruction (Caddy and Defeo 2003). It is possible to envisage the implementation of a protected area (approx. size of 290 ha) including the identified areas A and B (Fig. 5), which could be managed in this way ("no take zone"; strict controls against illegal harvesting).

\section{Conclusion}

- The present research confirms the suitability of the study area for Manila clam adults and juveniles, even though aggregated or patchy distributions were found and some decrease was noticed compared with bibliographical studies.

- The application of geostatistical tools allowed an estimation of the total stock resident in the area and revealed the presence of an important site exploitable as a nursery area.

- To face the significant decrease of Manila clam production in the Venice lagoon, which occurred after a period of uncontrolled exploitation, it is necessary to adopt a sustainable resource management strategy. Rational exploitation of the nursery areas will increase and optimize clam farming production, whilst the implementation of a protected area will contribute significantly to enhancing the productivity of natural populations.

Acknowledgements. This research was supported by the Ministry of Infrastructures and Transports - Magistrato alle Acque - through its concessionary Consorzio Venezia Nuova. The authors would like to thank the referees for the helpful suggestions and the language help that improved the quality of this paper.

\section{References}

Bellucci L.G., Giuliani S., Mugnai C., Frignani M., Paolucci D., Albertazzi S., Ruiz Fernandez A.C., 2012, Anthropogenic metal delivery in sediments of Porto Marghera and Venice lagoon (Italy). Soil Sediment Contam. 19, 42-57.

Breber P. 2002, Introduction and acclimatisation of the Pacific carpet clam, Tapes philippinarum, to Italian waters. In: Leppäkoski E., Gollasch S., Olenin S. (Eds.) Invasive aquatic species of Europe. Distribution, impacts and management. Kluwer Academic Publishers, Dordrecht, pp. 120-126.

Caddy J.F., Defeo O., 2003, Enhancing or restoring the productivity of natural populations of shellfish and other marine invertebrate resources. FAO Fish. Techn. Pap. 448, Rome.

Casale M., Giovanardi O., Grimm F., Orel G., Pessa G., 2001, Distribuzione ed abbondanza delle principali specie di molluschi bivalvi nella laguna di Venezia nell'estate 1999, con particolare riguardo per Tapes philippinarum (Adams \& Reeve, 1850). Biol. Mer. Medit. 8, 413-423.

GRAL, 2009, Adeguamento al Piano d'uso sostenibile delle aree in concessione per venericoltura. Gestione Risorse Alieutiche Lagunari.

GRAL, 2011, Piano per la gestione della in laguna di Venezia, 101.

Mauracher C., Pellizzato M., Trevisan G., 2010, Una valutazione tecnico-economica del comparto veneto della vongola. In: Trevisan G. (Eds.). Le vongole dell'alto adriatico tra ambiente e mercato. Franco Angeli, Milano, pp. 137-164.

Melaku Canu D., Campostrini P., Dalla Riva S., Pastres R., Pizzo L., Rossetto L., Solidoro C., 2011, Addressing sustainability of clam farming in the Venice Lagoon. Ecol. Soc. 16, DOI: 10.5751/ES04263-160326.

Morsan E.M., 2003, Spatial analysis and abundance estimation of the southernmost population of purple clam, Amiantis purpurata in Patagonia (Argentina). J. Mar. Biol. Assoc. UK 83, 1073-1082.

Nambu R., Saito H., Tanaka Y., Higano J., Kuwahara H., 2012, Wave actions and topography determine the small-scale spatial distribution of newly settled Asari clams Ruditapes philippinarum on a tidal flat. Estuar. Coast. Shelf Sci. 99, 1-9.

Ólafsson E.B., Peterson C.H., Ambrose W.G., 1994, Does recruitment limitation structure populations and communities of macroinvertebrates in marine soft sediments? The relative significance of pre- and post-settlement processes. Oceanogr. Mar. Biol. Ann. Rev. 32, 65-109.

O’Malley J., 2007, US Geological Survey ArcMap Sediment Classification Tool: Installation and User Guide. US Geological Survey Open-File Report 2007-1186, http://pubs.usgs.gov/of/ 2007/1186/

Paesanti F., Pellizzato, M., 2000, Tapes philippinarum. Manuale di divulgazione. Veneto Agricoltura edn. Padova.

Pellizzato M., Galvan T., Lazzarini R., Penzo P., 2011, Recruitment of Tapes philippinarum in the Venice lagoon (Italy) during 2002-2008. Aquac. Int. 19, 541-554.

Pellizzato M., Da Ros L., 2005, Clam farming quality as a management tool: a proposal based on recent studies in Northern Adriatic lagoons. Aquac. Int. 13, 57-66.

Penzo P., Galvan, T. , Pellizzato, M., 2003, Reclutamento ed accrescimento del seme di Tapes philippinarum in un area della laguna di Venezia. Biol. Mar. Medit. 10, 473-476.

Pessa G., Mion D., 2005, Variazioni nella distribuzione ed abbondanza di Tapes philippinarum (Adams \& Reeve, 1850) e Cerastoderma glaucum (Poiret, 1789) (Mollusca Bivalvia) in laguna di Venezia tra il 1999 ed il 2002. Biol. Mar. Medit. 12, 303-306.

Pranovi F., Giovanardi O., 1994, The impact of hydraulic dredging for short-necked clams, Tapes spp., on an infaunal community in the lagoon of Venice. Scient. Mar. 58, 345-353. 
Regione Emilia-Romagna, 2010, Aree marine di tutela istituite dalla Regione Emilia-Romagna. Primi interventi nella Sacca di Goro e nel mare. La Mandragora, Imola (Bo).

Sauriau P.G., Bacher C., 1991, Cartographie krigée des mollusques suspensivores compétiteurs trophiques des huîtres du bassin de Marennes-Oléron : implications pour la planification de l'échantillonnage. J. Rech. Océanogr. 16, 1-4.

Schlee J., 1973, Atlantic Continental Shelf and Slope of the United States: Sediment Texture of the Northeastern Part: US Geological Survey Professional Paper 529-L.

Shepard F.P., 1954, Nomenclature based on sand-silt-clay ratios. J. Sediment. Petrol. 24, 151-158.

Sladonja B., Bettoso N., Zentilin A., Tamberlich F., Acquavita A., 2011, Manila clam (Tapes philippinarum Adams \& Reeve, 1852) in the Lagoon of Marano and Grado (Northern Adriatic Sea, Italy): Socio Economic and Environmental Pathway of a Shell Farm. In: Sladonja B. (Ed.) Aquaculture and the environment A shared destiny, InTech Publisher, pp. 51-78.

Solidoro C., Bandelj V., Bernardi Aubry F., Camatti E., Ciavatta S., Cossarini G., Facca C., Franzoi P., Libralato S., Melaku Canu D., Pastres R., Pranovi F., Raichevich S., Socal G., Sfriso A., Sigovini M., Tagliapietra D., Torricelli P., 2010, Response of Venice lagoon ecosystem to natural and anthropogenic pressures over the last 50 years. In: Paerl H., Kennish M. (Eds.), Coastal Lagoons: Systems of Natural and Anthropogenic Change, CRC press, Taylor and Francis, pp. 483-511.
Sorokin Y.I., Giovanardi O., 1995, Trophic characteristics of the Manila clam (Tapes philippinarum Adams and Reeve). ICES J. Mar. Sci. 52, 853-862.

Tezuka N., Kamimura S., Hamaguchi M., Saito H., Iwano H., Egashira J, Fukuda Y., Tawaratsumida T., Nagamoto A., Nakagawa K., 2012, Settlement, mortality and growth of the asari clam (Ruditapes philippinarum) for a collapsed population on a tidal flat in Nakatsu, Japan. J. Sea Res. 69, 23-35.

Veneto Agricoltura and Provincia di Venezia, 2011. Piano per la gestione della venericoltura in laguna di Venezia.

Vincenzi S., Zucchetta M., Franzoi P., Pellizzato M., Pranovi F., De Leo G.A., Torricelli P., 2011, Application of a Random Forest algorithm to predict spatial distribution of the potential yield of Ruditapes philippinarum in the Venice lagoon, Italy. Ecol. Model. 222, 1471-1478.

Warren W.G., 1997, Spatial analysis of marine populations. Proc. Survey Method Section, SSC Annual Meeting, Florence, pp. $145-150$.

Zentilin A., Orel G., Zamboni R., 2007, L'introduzione in Europa di Tapes philippinarum (Adams \& Reeve, 1852), la vongola verace filippina. Ann. Ser. Hist. Nat. 2, 227-232.

Zonta R., Botter M., Cassin D., Pini R., Scattolin M., Zaggia L., 2007, Sediment chemical contamination of a shallow water area close to the industrial zone of Porto Marghera (Venice Lagoon, Italy). Mar. Pollut. Bull. 55, 529-542. 